\title{
O TEATRO DE AUGUSTO BOAL E A EDUCAÇÃO PROFISSIONAL EM SAÚDE
}

\author{
THE THEATER OF AUGUSTO BOAL AND THE VOCATIONAL EDUCATION IN HEALTH
}

Irene Leonore Goldschmidt ${ }^{1}$

Resumo O presente artigo discute as possibilidades da inserção do teatro na educação profissional em saúde, tendo como referência a proposta estética e pedagógica de Augusto Boal. A concepção de politecnia, ao defender para a formação dos trabalhadores uma integração entre trabalho, ciência e cultura, abre espaço para novas possibilidades nesse campo. Autores como Paulo Freire, na educação, e Augusto Boal, no teatro, convergem para a perspectiva de construção, por parte dos trabalhadores, de uma cultura e estética próprias, que reflitam sua concepção de mundo. Buscamos pensar de que forma as proposições teatrais de Augusto Boal podem ser apropriadas para o campo da educação em saúde, tentando estabelecer afinidades e relações entre essas duas práticas, dentro da ótica de uma educação para os trabalhadores da saúde que lhes propicie uma formação humana para além daquela requerida de forma mais imediatista pelo mercado de trabalho.

Palavras-chave teatro; Augusto Boal; educação em saúde; formação humana.
Abstract This article discusses the possibilities of including the performing arts in professional health education based on the aesthetic and pedagogical proposal set forth by Augusto Boal. The polytechnic concept, by advocating that workers' training include an integration of work, science and culture, opens space for new possibilities in this field. Authors such as Paulo Freire, in the field of education, and Augusto Boal, in theater, converge towards the prospect of the workers building both a culture and aesthetics of their own to reflect their world view. Our goal was to think about how Augusto Boal's theatrical propositions may be appropriate for the field of health education in an attempt to establish relationships and affinities between these two practices, from the perspective of health worker education, that they will provide the professionals with a more humanistic type of training that will extend beyond the labor market's more immediate requirements.

Keywords theater; Augusto Boal; health education; humanistic education. 


\section{Introdução}

Com o desenvolvimento da ciência a partir do século XVII, a forma de organização do conhecimento sofre grandes mudanças. Começa a ser construída uma nova visão de mundo, impulsionada pelas proposições de Kepler de que o universo é regido pelas mesmas leis, leis de natureza estritamente matemática. O entendimento da realidade como intrinsecamente racional e passível de ser explicada e entendida por ideias e conceitos levou também à crescente delimitação dos campos de conhecimento, e a arte e a ciência passaram a ser situadas em campos estanques, com pouca ou nenhuma intercomunicação.

Por isso, a ideia de utilização do teatro como um conteúdo didático inserido na educação profissional em saúde pode, à primeira vista, causar certa estranheza. Acrescente-se, ainda, o histórico da formação em saúde, que tradicionalmente tem sido marcada pelo predomínio do modelo biomédico, centralizado na figura do médico e na autoridade do saber técnico e científico, com a desvalorização do saber popular.

Dentro da educação profissional em saúde, a concepção tecnicista de educação, que se limita à transmissão de conhecimentos operacionais para a execução de técnicas sem se preocupar com seus fundamentos científicos e filosóficos nem com sua contextualização no todo social, vem dando lugar à concepção de politecnia, que, segundo Pereira e Ramos (2006),

(...) buscava e busca romper com a dicotomia entre educação básica e técnica, resgatando o princípio da formação humana em sua totalidade. Em termos epistemológicos e pedagógicos, esse ideário defendia um ensino que integrasse trabalho, ciência e cultura, visando ao desenvolvimento de todas potencialidades humanas (Pereira e Ramos, 2006, p. 79).

Nessa perspectiva, a educação profissional em saúde vem se constituindo num campo que tem possibilitado experiências alternativas e transformadoras, a exemplo daquela que a Escola Politécnica de Saúde Joaquim Venâncio (EPSJV), no Rio de Janeiro, desenvolve desde 2009, com a inserção de oficinas de literatura e teatro na formação técnica de agentes comunitários de saúde.

Paulo Freire, importante referência pedagógica para as Escolas Técnicas do SUS, que associam a educação com o mundo do trabalho, herança do Projeto Larga Escala, 2 aponta como falso o dilema frequentemente colocado para a educação entre uma concepção humanista e a tecnologia. Para Freire, a defesa da via tecnicista, que considera a perspectiva humanista como "uma forma de retardar as soluções mais urgentes", é um erro tão nefasto quanto a falsa visão de humanismo "que vê na tecnologia a razão dos males do homem moderno". As duas perspectivas não se excluem; muito pelo contrário, se complementam. 
Se o meu compromisso é realmente com o homem concreto, com a causa de sua humanização, de sua libertação, não posso por isso prescindir nem da ciência, nem da tecnologia, com as quais vou me instrumentando para melhor lutar por essa causa. Por isso mesmo não posso reduzir o homem a um simples objeto da técnica, a um autômato manipulável (Freire, 2010, p. 22).

Freire defende que o ato de conhecer está intimamente associado à transformação na consciência e na 'leitura do mundo'; para Freire, esta transformação da percepção não se faz mediante um trabalho em nível puramente intelectualista (1975, p. 77). A ação educativa deve incidir também no campo cultural, nas formas de pensar, ver e sentir, para que os novos conhecimentos venham a se integrar ao universo gnosiológico preexistente, transformando-o em sua totalidade.

A transformação cultural (...) exige uma ação no campo da 'cultura popular', que, interferindo deliberadamente no campo da percepção, ajudará a acelerar a própria transformação cultural. (Freire, 1975, p. 62).

A dramatização é um processo valorizado na educação freiriana: em um texto escrito para um seminário realizado, em 1968, por uma das Equipes Centrais que coordenavam trabalhos de alfabetização no Chile, Freire propõe a dramatização, por camponeses, de fatos por eles vividos, "não apenas como uma forma de estimular a expressividade dos camponeses, mas também de desenvolver a sua consciência política" (Freire, 1976, p. 29).

\section{Augusto Boal e o teatro do oprimido}

Para pensarmos em formas de desenvolver processos teatrais que apoiem a formação dos trabalhadores da saúde numa perspectiva crítica, uma importante referência é o nome de Augusto Boal, teatrólogo que desenvolveu suas teses em obras como $O$ teatro do oprimido e A estética do oprimido. Suas ideias sofreram influência do pensamento de Paulo Freire, levado agora para o campo da estética, assim como do teatro crítico e pedagógico de Bertolt Brecht, principalmente no que se refere ao estímulo para desenvolver no espectador uma postura crítica diante do que lhe é teatralmente apresentado. No entanto, Boal dá um passo à frente:

Aristóteles propõe uma poética em que os espectadores delegam poderes ao personagem para que este atue e pense em seu lugar; Brecht propõe uma poética em que o espectador delega poderes ao personagem para que este atue em seu lugar, 
mas se reserva o direito de pensar por si mesmo, muitas vezes em oposição ao personagem. (...) O que a poética do oprimido propõe é a própria ação! (Boal, 1988, p. 138).

O teatro do oprimido começa a ser formulado na década de 1970, com a ideia de uma criação a partir da realidade dos participantes, e sua primeira forma foi o teatro-jornal, que construía sua dramaturgia por meio de notícias de jornal.

Partindo da proposição básica do envolvimento do espectador a fim de que ele entre em cena e atue criticamente diante de uma situação de opressão, tentando desfazê-la, Boal elaborou uma série de formatos, que podem ser infinitamente diversificados, dependendo da situação.

Em 1971, exilado na Argentina, ali continuou seu trabalho, criando o teatro invisivel, realizado em lugares públicos. Nessa modalidade, "os rituais teatrais são abolidos: existe apenas o teatro, sem suas formas velhas e gastas" (Boal, 1988, p. 170). Os atores começam a encenação como se estivessem vivendo uma situação real, sempre dentro de uma perspectiva de crítica social, criando situações polêmicas que acabam mobilizando os presentes. Esses, desconhecendo tratar-se de uma encenação, participam espontaneamente, tornando-se protagonistas sem disso ter consciência. Para incentivar esse tipo de participação, é importante que os temas apresentados digam respeito à vida dessas pessoas.

No teatro-fórum, uma das modalidades mais utilizadas pelo teatro do oprimido, uma situação de opressão, inicialmente representada por atores, é construída teatralmente. Sua proposta é de que o espectador, a partir de determinado momento, intervenha na representação, substituindo o ator que está fazendo o papel do oprimido e atuando no sentido de desfazer a situação de opressão. O teatro-fórum é definido por Boal como "um tipo de luta ou jogo, com regras descobertas, e não inventadas" (2007, p. 28). Essas regras são necessárias para que se obtenha o efeito desejado, ou seja, a descoberta dos mecanismos que produzem e mantêm a opressão, e das táticas e estratégias possíveis para desfazê-la.

O texto inicial deve apresentar os personagens com clareza, identificando a sua ideologia, revelada por meio da expressão corporal dos atores, que devem realizar atividades significativas, com gestos marcados. Cada gesto e movimentação têm a sua razão de ser. Isso é importante para que, ao substituir o ator, o espectador não se limite a discursar, mas 'atue'. O figurino deve conter elementos - que os 'espect-atores' também possam utilizar -, essenciais ao personagem.

Ao lado da preocupação com a clara exposição e a discussão do problema, o teatro-fórum continua sendo teatro e, como tal, deve ser fonte de prazer estético. Assim, tão importante quanto o texto, é a organização da cena no 
espaço. Os participantes são estimulados a não apenas verbalizarem suas ideias, mas a fazerem isso teatralmente, com criatividade, utilizando recursos como a música, a dança e as linguagens simbólica e metafórica.

O teatro-imagem foi criado por Boal quando, ao trabalhar com alfabetização no Peru, deparou-se com mais de 45 dialetos indígenas, além do quíchua. Por isso, o espectador, sem usar palavras, intervém na cena, 'esculpindo', com o corpo dos atores, uma imagem que represente o seu pensamento sobre o tema em questão. Outros espectadores podem entrar e modificar o que foi feito pelos anteriores, construindo novas 'imagens', que representem o seu ponto de vista.

O teatro-fotonovela, montado sobre o modelo da estrutura dramática das novelas, porém reinterpretado pelos participantes com base em sua realidade local, oferece farto material para discussão. A comparação entre a versão e a novela como apresentada na televisão também leva à desmistificação da linguagem midiática. A linguagem da telenovela é a primeira referência para os atores comunitários, aquela que eles procuram reproduzir quando instados a desenvolver alguma representação. “Quando se consegue mostrar-lhes que o teatro são eles e não as telenovelas, os resultados são sempre esplêndidos" (Boal, 1996, p. 94). Se o ator para de tentar imitar as posturas dos personagens de novela e começa a mostrar como ele e as pessoas reais que ele conhece são, interpretar fica mais fácil e prazeroso - e a cena adquire um interesse todo especial para aqueles que a veem e nela se reconhecem.

Todas essas experiências de teatro popular visam primordialmente à libertação do espectador das visões acabadas do mundo, assim como ao desnudamento das superestruturas e dos rituais que 'coisificam' as relações humanas e que impõem a cada pessoa papéis e máscaras específicos, inerentes à sua inserção social. Essa concepção se afina com a perspectiva da educação crítica, ao propiciar o domínio de uma nova linguagem, que, por sua vez, abre possibilidades para novas formas de conhecimento da realidade:

Cada linguagem é absolutamente insubstituivel. Todas as linguagens se complementam no mais perfeito e amplo conhecimento do real. Isto é, a realidade é mais perfeita e amplamente conhecida através da soma de todas linguagens capazes de expressá-la. (Boal, 1988, p. 137, grifos nossos).

\section{A estética do oprimido e educação profissional em saúde}

Na sua derradeira obra, A estética do oprimido, Boal aprofunda a questão da construção de uma estética própria por parte dos oprimidos, e destaca a existência de duas formas de pensamento: o 'simbólico', que se dá mediante as 
palavras, e o 'sensível', por meio de sons e imagens. Assim, “o ato de pensar com palavras tem início nas sensações, e sem elas não existiria, embora delas se desprenda e se autonomize até a sua mais total abstração" (Boal, 2009 , p. 27). No que diz respeito à compreensão, a da linguagem simbólica é mais lenta, porque ela precisa ser decodificada, ao passo que a percepção sensível se dá de imediato.

Boal considera que o "analfabetismo das imagens e sons" é pior do que o "analfabetismo das letras", porque ele aliena o indivíduo da produção da sua arte e da sua cultura. O pensamento sensível, segundo Boal, representa a libertação dos oprimidos das ideias dominantes de uma sociedade, pois gera criação de cultura, em vez do seu consumo passivo.

O uso da palavra, embora permitindo um nível de abstração do pensamento e sendo elemento indispensável para o diálogo, obscurece nossa percepção estética. Palavras são significantes polissêmicos e estão carregadas de significados subjetivos e culturais. Podem ser manipuladas, esvaziadas, distorcidas. Portanto, o que nos dizem os sentidos não deve ser ignorado ou colocado em posição inferior.

A estética do oprimido visa não apenas tornar o espetáculo agradável, mas expor as mentiras e as mistificações que, disseminadas pelo pensamento hegemônico no senso comum, acabam sendo naturalizadas e aceitas como verdades. Longe de ser uma técnica ou um método, o que de forma alguma se coadunaria com o pensamento do autor, a estética do oprimido é uma proposta de intervenção baseada em alguns princípios: oferecer meios para o desenvolvimento de uma cultura própria dos participantes, com base em suas possibilidades, estimulando-os a buscarem seus caminhos; no caso do teatro, buscar apresentar não 'a realidade' acrítica, mas revelar as forças sociais ocultadas nos fenômenos e a correlação das forças em conflito; mostrar que todo ser humano tem potencial criativo e, portanto, a possibilidade de desenvolver processos artísticos.

Ao analisarmos mais detidamente o fazer teatral dentro dessa perspectiva, vamos nos deparar com vários aspectos inerentes à prática teatral que apontam para uma ampliação dos horizontes daqueles que com ela se envolvem. Ela possibilita ao trabalhador da saúde elaborar uma nova visão de mundo na qual possa perceber-se como elemento transformador da realidade, concebida agora dentro de uma perspectiva crítica, ou seja, não como dada, mas dinâmica, a realidade como resultante do processo de interação dos seres humanos em sociedade, podendo, portanto, ser modificada pela ação humana. Dentre os aspectos da prática teatral que implicam a ampliação de horizontes para os seus participantes/espectadores, podemos ressaltar:

1) outros canais de apreensão da realidade além da racionalidade, como a percepção, a sensibilidade e a intuição; 
2) consciência corporal, mediante o conhecimento do próprio corpo e de suas possibilidades expressivas. Para tornar o espectador ator, o ponto de partida é fazê-lo conhecer e dominar o próprio corpo, identificando e desfazendo os enrijecimentos musculares causados pelos papéis sociais que todos somos levados a desempenhar. Com isso, segundo Boal, busca-se tornar o corpo expressivo, estimulando outras formas de comunicação que não a verbal. Além disso, para o trabalhador de saúde, o maior conhecimento sobre o corpo é duplamente importante, por ser ele também o seu objeto de trabalho;

3) capacidade de se colocar no lugar do outro, ampliando a visão de mundo pela incorporação de novas perspectivas;

4) a igual valorização de práticas e saberes relativos ao processo de construção teatral, como a confecção de cenários e figurinos, a execução musical, a escrita da dramaturgia e o trabalho dos próprios atores, sem distinção valorativa entre trabalho intelectual e manual, que compromete e responsabiliza a todos igualmente com o produto do trabalho, desenvolvendo autoestima, autoconfiança e compromisso social. O espírito de grupo é condição importante para um trabalhador de saúde que estará inserido em uma equipe multidisciplinar.

Para os trabalhadores que têm como atribuições importantes desenvolver ações educativas e de mobilização social, como é o caso dos agentes e técnicos de vigilância em saúde ou dos agentes comunitários de saúde, o conhecimento sobre o processo de criação teatral pode ampliar em muito o poder educativo dessas ações.

\section{Considerações finais}

Arte e criação se configuram na nossa história como forças que nos impulsionam não só para a luta pela sobrevivência, mas também para a busca pela satisfação de outras necessidades igualmente importantes, como a do sentido de beleza e de harmonia. Por meio da arte, o homem conhece o mundo não só pela razão, mas também pelos sentidos, e expressa percepções que não poderiam ser comunicadas apenas por palavras.

Uma educação para trabalhadores da saúde que busque formar seres humanos críticos e transformadores, e não meras peças de engrenagem, precisa lançar mão de todas as possibilidades levem a isso e que rompam com uma visão subjetivista, que compreende o fenômeno isolado da totalidade histórica.

Ao propiciar o domínio de uma nova linguagem, são abertas perspectivas de novas formas de conhecimento da realidade. A criatividade, capacidade humana que Ostrower (1987) destaca como primordial para que o ser 
humano possa se apropriar do mundo em que vive, é o elemento que Boal nos oferece para potencializar processos educativos questionadores de verdades erigidas em eternas.

Desmistificando a concepção que defende ser a arte uma atividade especial passível de ser praticada unicamente por iniciados ou privilegiados, dotados de uma genialidade particular, os trabalhadores da saúde, ao criarem a sua própria arte, podem derrubar as barreiras que os impedem de agir e criar, e de, com isso, transformar o mundo.

\section{Notas}

1 Farmacêutica sanitarista da Secretaria de Estado de Saúde do Rio de Janeiro, Rio de Janeiro, RJ, Brasil. Mestre em Educação Profissional em Saúde pela Escola Politécnica de Saúde Joaquim Venâncio, Fundação Oswaldo Cruz (EPSJV/Fiocruz). <irenegolds@gmail.com> Correspondência: Rua Monte Alegre, 364, apto. 401, CEP 20240-195, Santa Teresa, Rio de Janeiro, RJ, Brasil.

2 Projeto que, na década de 1980, visou à qualificação dos trabalhadores, de nível médio e fundamental, já inseridos nos serviços de saúde. Ver Pereira e Ramos, 2006.

\section{Referências}

BOAL, Augusto. A estética do oprimido. Rio de Janeiro: Garamond, 2009.

Jogos para atores e não atores. 10. ed. Rio de Janeiro: Civilização Brasileira, 2007.

Teatro do Oprimido e outras poéticas políticas. 5. ed. Rio de Janeiro: Civilização Brasileira, 1988.

BRECHT, Bertolt. Teatro dialético. Rio de Janeiro: Civilização Brasileira, 1967.

CHAUÍ, Marilena. Convite à filosofia. São Paulo: Ática, 2002.
FREIRE, Paulo. Ação cultural para a liberdade. Rio de Janeiro: Paz e Terra, 1976.

Educação e mudança. 32. reimp. Rio de Janeiro: Paz e Terra, 2010.

Extensão ou comunicação? 2. ed. Rio de Janeiro: Paz e Terra, 1975.

KIRCHOF, Edgar Roberto. A estética antes da estética. Canoas: Ulbra, 2003.

LINHARES, Ângela Maria Bessa. O tortuoso e doce caminho da sensibilidade. Ijuí: Unijuí, 1999. 
OSTROWER, Fayga. Criatividade e processo de criação. 17. ed. Rio de Janeiro: Vozes, 1987.
PEREIRA, Isabel Brasil; RAMOS, Marise Nogueira. Educação profissional em saúde. Rio de Janeiro: Editora Fiocruz, 2006.

Recebido em 29/07/2011

Aprovado em 25/10/2011 